\title{
Prevalence of Worm Infection in Yankasa sheep and West African dwarf goats in Lafia Town and Environs, Nigeria.
}

\author{
D. I. Hassan ${ }^{1 *}$, S.T. Mbap ${ }^{2}$ and S. A. Naibi ${ }^{2}$ \\ ${ }^{I}$ Department of Animal Science, College of Agriculture, Lafia, Nasarawa State, Nigeria. \\ 2 Animal Production Programme, Abubakar Tafawa Balewa University Bauchi, Bauchi state. Nigeria.
}

\begin{abstract}
The study was conducted in Lafia town, districts and wards over a 12 months period (May, 2010 April, 2011) to investigate the prevalence of helminthosis/ eimeria infection in Yankasa sheep and West African dwarf goats. A total of 864 faecal samples comprising 432 each of Yankasa sheep and West African dwarf goats were evaluated. Worm prevalence was higher among Yankasa sheep than West African dwarf goats. Prevalence according to age groups among Yankasa sheep were, above 12 months (34.7\%), $6-12$ months (28.7\%) and less than 6 months (2.1\%) while West African dwarf goats above 12 months had the highest prevalence of $39.4 \%, 6$ -12 months $(20.8 \%)$ and less than 6 months $(2.3 \%)$. The highest prevalence of $21.29 \%$ in Yankasa sheep was obtained in the late rains followed by 15.97, 14.81and 13.43\% during early rains, early and late dry seasons respectively. For West African dwarf goats the highest prevalence was $17.12 \%$, during late rains followed by $16.73,16.20$ and $12.73 \%$ during early rains, early and late dry seasons respectively. Furthermore sheep were more burdened than goats. Female sheep and goats had higher degree of infection during the rainy season while male counterparts showed higher degree of infection during the dry season. In the study area therefore, preferential rearing of Yankasa sheep should be exploited and greater attention should be paid to West African $d$ warf goats, older sheep and goats and, rainy season in worm/ eimeria control.
\end{abstract}

Key words: Prevalence, Worm, Yankasa sheep, West African dwarf goats, Lafia

\section{Introduction:}

Africa has about 205 million sheep and 174 million goats representing approximately 17 and $31 \%$ of the world's totals respectively (FAO, 1990). Within the continent, the distributions of these small ruminants vary widely showing higher concentration in the dry than humid areas. Nigeria's small ruminant population is about 22.1 million sheep and 34.5 million goats, representing about $63.7 \%$ of the total domestic grazing livestock (Lamorde, 1997; Shaib et al., 1997). They are also concentrated in the northern dry-hot than the southern humid parts of Nigeria.

The role of livestock in human development is enormous. Livestock production plays a crucial role in socio-economic changes such as improvement in income and quality of life. They serve primarily as sources of meat, but also provide milk and skin (Broomker et al., 1994). Sheep and goats produce only about $16 \%$ of the world's meat, despite high contribution to total world livestock population. Milk and skin production is similarly low since these potentials have not been fully exploited.

African small ruminants produce only 14 and $15 \%$ of the world's milk and skin respectively but $50 \%$ of meat consumption in Nigeria (ILCA, 1987). Furthermore in Nigeria they provide about $36.5 \%$ of total protein intake (NISER/CBN, 1991) which still falls short of the minimum animal protein requirement of 50 gram recommended by FAO/WHO (1993). They however, have potentials for improvement since they have high reproductive efficiency even under harsh environment. Lamorde (1996) reported that when properly harnessed, these farm animals can meet the protein requirement of the nation. Proteins from animal sources are needed for physical and intellectual development as well as for developing immunity against diseases (Atinmo and Akenyele, 1983).

Many research rank helminthosis, especially in the form of parasitic gastroenteritis, along with PPR and pneumonia as the major constraints to increase sheep and goat production in the humid zone. The prevalence and seasonal distribution of gastro intestinal parasites of small ruminants have been reported from most parts of the world and in Nigeria (Cheijina, 1986; Nwosu et al., 1996; Adejinmi and Harrison, 1996). In Africa, about $97 \%$ of sheep and goats are carriers of gastrointestinal parasites.

Helminthosis therefore has long been recognized and still remains a problem responsible for losses in ruminant production in almost all regions of the world. Economic losses are caused through lower fertility, reduced work capacity, involuntary culling, reduction in food intake and lower weight gains and milk production, treatment costs, and mortality in heavily parasitized animals (Gatongi, et al., 1997; Perry and Randolph, 1999; Perry, et al., 2002; Tibbo, et al., 2006). Matika et al. (2002) reported that, helminthosis is one disease aspect that has not received adequate attention. This is probably because their effects are not generally immediately manifested through multiple mortalities as in bacterial and viral infection. In addition most small 
holder and backyard practitioners have little or no knowledge about this disease. Yet small ruminant infection has significant effect not only on the animals but also on the farmer's livelihood including general welfare and health status. The control of helminthosis has largely been limited to the use of chemotherapeutic agents with high efficacy and are relatively safe Alawa et al. (2008).

\section{Study Area}

\section{Materials And Methods}

The study was conducted in Lafia and environs in Nasarawa South senatorial district of Nasarawa state, Nigeria. Lafia is the state capital of Nasarawa state which lies between latitude $7^{\circ} 45^{\prime}$ and $9^{\circ} 37^{\prime}$ East. It shares boundary with Kaduna a state to the north, Plateau state to the east, Taraba and Benue state to the south, while Kogi and Federal Capital Territory flank it to the west (Binbol and Markus 2005). It has an altitude of $181.5 \mathrm{~m}$ above sea level. The state has a land area of 27,137.8 square kilometers with a population of 1,863,275. Lafia is located on longitude $8.30^{\circ} \mathrm{N}$ and latitude $8.34^{\circ} \mathrm{E}$. It has two distinct seasons (NPC, 2006; Aboki et al., 2007). The dry season is from November to April and the wet season from May to October. During the period study most of the rains fell between the months of May and October. The driest months were December, January and March. The mean relative humidities varied from $36-86 \%$ with the lowest values from December to April. The mean monthly maximum temperatures were from $31.8{ }^{\circ} \mathrm{C}-39.1{ }^{\circ} \mathrm{C}$ and minimum from $17.1{ }^{\circ} \mathrm{C}-26.2{ }^{\circ} \mathrm{C}$ (NIMET, 2009). The geographical area is largely inhabited by people whose main occupation is subsistence agriculture; including the rearing of small ruminants; others are artisans, civil servants, traditionalists and herbalists.

\section{Soil and Vegetation}

Aboki et al. (2007) reported that, the major soil units of Lafia and environs are inceptisols. They developed from the recently accumulated alluvial sediments of flood plains. The soils are moist and poorly drained almost throughout the year with soil water table being high. Lafia lies within the guinea savanna. Though largely southern guinea savanna, there are some elements of northern guinea savanna intersperse thickets, grasslands, tree savanna, fringing woodlands or gallery forest along the valleys (Lloeje, 1985). The trees are between $15-20 \mathrm{~m}$ and grasses up to 5 meters tall. In the rainy season grasses and leaves are green and fresh, while in the dry season, they are destroyed through withering or bush fire (Aboki et al., 2007).

\section{Experimental Animals}

The population under study was Yankasa Sheep and West African Dwarf Goat in Lafia and its environs. Eight hundred and sixty-four Yankasa Sheep and West African Dwarf goats of various sexes and ages belonging to 135 farmers from the districts/wards were included in the survey. The management was the extensive and semi-intensive systems. The extensive system was usually carried out during the dry season whereby animals were allowed to roam and fed for themselves without a shepherd during the day and returned to their owners homestead in the evening. During the rainy season when arable crops grow, animals were semiintensively managed. They were taken out for grazing from late morning till evening where herd size was small, animals were tethered.

\section{Faecal sample collection and Analysis}

Faecal samples were collected directly from the rectum using clean polythene bags. Collections were carried out weekly from the month of May, 2010 to April, 2011. Total samples collected were 864, this comprised of 432 and 432 samples from the Yankasa Sheep and West African dwarf goat respectively. The samples also consisted of 209 and 223 from male and female Yankasa sheep and, 206 and 226 from male and female West African dwarf goats respectively. Samples were properly labeled with masking tape indicating breed, sex and age. They were stored in a refrigerator at $4^{\circ} \mathrm{C}$ and transported to the National Veterinary Research Institute Vom, Plateau state for analysis.

Faecal samples were examined for the presence of eggs of the various helminthes species and number of eggs per gram of faeces (EPG) determined using the modified McMaster technique (Whitlock, 1948; Thienpont et al., 1986).

\section{Statistical Analysis}

The data generated were analyzed using percentage and chi-square test procedures as contained in the Statistical Package for Social Sciences (SPSS version 17, 2011) to determine statistical differences in prevalence/ faecal egg count (FEC) among the following:

(i) Yankasa sheep and west African dwarf goat.

(ii) Sex: male and female

(iii) Age group in months above 12, 6-12 and $<6$ 
(iv) Four season:

(v) Early rain (May - July)

\section{Results}

General prevalence of helminth parasites and eimeria in Yankasa sheep and West African dwarf goats Table 1 showed the prevalence of helminthosis and eimeria. Out of 864 hosts observed 553 hosts were found to be infected. The overall outcome of the study was $64 \%$ prevalence. This study showed $71.42 \%$ of nematode infection, $2.9 \%$ trematode infection, $1.27 \%$ cestode infection and $24.41 \%$ coccidia infection. The total number of genera observed was 11 in number. 7 genera of nematode, 2 genera of trematode, 1 genera of cestode and 1 Coccidia were observed. The highest prevalence was shown by Heamonchus $(39.24 \%)$ and lowest prevalence was shown by Ascaris lumbricoides which were found to infect only West African dwarf goats $(0.90 \%)$.

Table: 1 Observed genera of different classes with prevalence percentages in Yankasa sheep and West African dwarf goats

\begin{tabular}{lllr}
\hline S/Ao. & Class & Genera of helminths & Percentage \\
\hline 1 & Nematoda & Ascaris lumbricoides & 0.90 \\
& & Bunostomum & 1.08 \\
& & Chabertia & 5.61 \\
& & Haemonchus & 39.24 \\
& & Oesophagostomum & 1.27 \\
2 & Strongyloides & 11.21 \\
3 & Trematoda & Trichostrongylus & 12.11 \\
4 & Cestoda & Fasciola & 1.27 \\
& Coccida & Paramphistomum & 1.63 \\
\hline
\end{tabular}

Effect of breeds, sex and age on helminthosis prevalence

Table 2 shows that, 432 Yankasa sheep was observed for helminths prevalence $65.5 \%$ showed present of parasites while $34.5 \%$ showed no parasites. In West African dwarf goats a total of 432 were used for helminthosis prevalence $62.5 \%$ showed infection while $37.5 \%$ no infection. The influence of the breed was not significant.

The influence of the sex of Yankasa sheep and West African dwarf goats shown in Table 2 was not significant with the highest prevalence in female $33.1 \%$ followed by $32.4 \%$ in male Yankasa sheep. The West African dwarf goats had the highest prevalence in female $33.1 \%$ and $29.4 \%$ was observed in male. The effect of sex on helminths prevalence showed a not significant difference among the breeds.

Table 2 showed the effect on prevalence with Yankasa sheep above 12 months had the highest prevalence of $34.7 \%$ followed by $28.7 \%$ for $6-12$ months while those less than 6 months had the least prevalence of $2.1 \%$ which shows a significances difference $(\mathrm{P}<0.01)$. Age had a significant $(\mathrm{P}<0.01)$ effect on the prevalence with West African dwarf goats above 12 months had the highest prevalence of $39.4 \%$ followed by $20.8 \%$ for $6-12$ months while those less than 6 months had the lowest prevalence of $2.3 \%$.

Table 2:Helminthosis prevalence by status in breed, sex and age of the animals

\begin{tabular}{|c|c|c|c|c|c|}
\hline Variables & $\begin{array}{c}\text { Paras } \\
\text { No. }\end{array}$ & $\begin{array}{c}\text { esents } \\
(\%)\end{array}$ & $\begin{array}{r}\text { Para } \\
\text { No. }\end{array}$ & $\begin{array}{r}\text { bsent } \\
(\%)\end{array}$ & $\mathbf{X}^{2}$ \\
\hline \multicolumn{6}{|l|}{ Yankasa sheep } \\
\hline $\begin{array}{l}\text { Overall } \\
\text { Sex }\end{array}$ & 283 & 65.5 & 149 & 34.5 & \\
\hline Male & 140 & 32.4 & 68 & 15.7 & ns \\
\hline Female & 143 & 33.1 & 81 & 18.8 & \\
\hline \multicolumn{6}{|l|}{ Age } \\
\hline$<6$ months & 9 & 2.1 & 4 & 0.9 & \\
\hline $6-12$ months & 124 & 28.7 & 41 & 9.5 & $* *$ \\
\hline$>12$ months & 150 & 34.7 & 104 & 24.1 & \\
\hline \multicolumn{6}{|c|}{ West African Dwarf goats } \\
\hline Overall & 270 & 62.5 & 162 & 37.5 & \\
\hline \multicolumn{6}{|l|}{ Sex } \\
\hline Male & 127 & 29.4 & 80 & 18.5 & ns \\
\hline Female & 143 & 33.1 & 82 & 19.0 & \\
\hline \multicolumn{6}{|l|}{ Age } \\
\hline$<6$ months & 10 & 2.3 & 0 & 0 & \\
\hline $6-12$ months & 90 & 20.8 & 47 & 10.9 & $* *$ \\
\hline$>12$ months & 170 & 39.4 & 115 & 26.6 & \\
\hline
\end{tabular}




\section{Influence of helminths count on sex and age of the animals}

Table 3 showed the influence of count on sex and age helminthosis prevalence in Yankasa sheep and West African dwarf goats. The highest prevalence of $53.9 \%$ followed by $37.5 \%$ and $8.6 \%$ in single, none and double count while no triple in Yankasa sheep respectively. The West African dwarf goats had also the highest in single with $51.2 \%$ followed by none count $34.5 \%$ while double and triple had $14.1 \%$ and $0.2 \%$ respectively. The influence of sex on helminths count is shown in Table 3. The effect of count on the sex had not significant difference among the male and female Yankasa sheep. On the West African dwarf goats, the sex also had not significant difference $\left(\mathrm{X}^{2}=4.866, \mathrm{P}<0.01\right.$, d.f. $\left.=3\right)$.

Age had a significant $(\mathrm{P}<0.01)$ effect on prevalence with Yankasa sheep above 12 months had the highest prevalence of (32.4\%) single count compare to (19.7\%) for $6-12$ months and (1.9\%) least prevalence of less than 6 months as shown in Table 3. West African dwarf goats had a significant $(\mathrm{P}<0.01)$ effect on prevalence above 12 months with highest prevalence of $(25.2 \%)$ single count compare to (24.1\%) least prevalence of $(1.9 \%)$ less than 6 months.

Table 3: Helminthosis prevalence by count on breed, sex and age of the animals

\begin{tabular}{|c|c|c|c|c|c|c|c|c|c|}
\hline \multirow[b]{3}{*}{ Variables } & \multicolumn{8}{|c|}{ Count } & \multirow{3}{*}{$\mathbf{X}^{2}$} \\
\hline & \multicolumn{2}{|c|}{ None } & \multicolumn{2}{|c|}{ Single } & \multicolumn{2}{|c|}{ Double } & \multicolumn{2}{|c|}{ Triple } & \\
\hline & No. & $(\%)$ & No. & $(\%)$ & No. & $(\%)$ & No. & $(\%)$ & \\
\hline \multicolumn{10}{|c|}{ Yankasa sheep } \\
\hline \multicolumn{10}{|l|}{ Sex } \\
\hline Male & 68 & 15.7 & 116 & 26.9 & 24 & 5.6 & 0 & 0.0 & \\
\hline Female & 81 & 18.8 & 105 & 24.3 & 37 & 8.6 & 1 & 0.2 & 1.610 \\
\hline \multicolumn{10}{|l|}{ Age } \\
\hline$<6$ months & 4 & 0.9 & 8 & 1.9 & 1 & 0.2 & 0 & 0.0 & \\
\hline $6-12$ months & 41 & 9.5 & 104 & 24.1 & 19 & 4.4 & 1 & 0.2 & $11.552 * *$ \\
\hline$>12$ months & 104 & 24.1 & 109 & 25.2 & 41 & 9.5 & 0 & 0.0 & \\
\hline \multicolumn{10}{|c|}{ West African dwarf goats } \\
\hline Overall & 162 & 37.5 & 233 & 53.9 & 37 & 8.6 & 0 & 0.0 & \\
\hline \multicolumn{10}{|l|}{ Sex } \\
\hline Male & 80 & 18.5 & 111 & 25.7 & 16 & 3.7 & 0 & 0.0 & \\
\hline Female & 82 & 19.0 & 122 & 28.2 & 21 & 4.9 & 0 & 0.0 & ns \\
\hline \multicolumn{10}{|l|}{ Age } \\
\hline$<6$ months & 0 & 0.0 & 8 & 1.8 & 1 & 0.2 & 0 & 0.0 & \\
\hline $6-12$ months & 47 & 10.9 & 85 & 19.7 & 5 & 1.2 & 0 & 0.0 & $6.797 *$ \\
\hline$>12$ months & 115 & 26.6 & 140 & 32.4 & 31 & 7.2 & 0 & 0.0 & \\
\hline
\end{tabular}

\section{Effect on type of infection on breeds, sex and age of the animals}

Table 4 showed the influence of type of infection on breeds, sex and age in Yankasa sheep and West African dwarf goats. The type of infection in Yankasa sheep is low $(11.8 \%)$ in female followed by male $(7.2 \%)$ as compare severe $(1.6 \%)$ female and $(2.5 \%)$ male. These show that there was no association between the level of EPG and the degree of infection although higher EPG was recorded in the moderate degree of infection in male and female sheep (19.7\%). The West African dwarf goats had also the highest in moderate with (29.2\%) in female followed by $(28.5 \%)$. The effect of sex on helminths prevalence showed a not significant difference among the breeds.

Age had a significant $(\mathrm{P}<0.05)$ effect on prevalence with Yankasa sheep above 12 months had the highest prevalence of $(31.3 \%)$ moderate compare to $(24.3 \%)$ for $6-12$ months and $(2.1 \%)$ least prevalence of less than 6 months as shown in Table 4. West African dwarf goats had a significant $(\mathrm{P}<0.05)$ effect on prevalence above 12 months with highest prevalence of $(25.7 \%)$ moderate compare to $(12.5 \%)$ for $6-12$ months and least prevalence of $(1.2 \%)$ less than 6 months.

Table 4: Helminthosis prevalence by type of infection on breed, sex and age of the animals

\begin{tabular}{|c|c|c|c|c|c|c|c|c|c|}
\hline \multirow[t]{2}{*}{ Variables } & \multicolumn{2}{|c|}{ None } & \multicolumn{2}{|c|}{ Low } & \multicolumn{2}{|c|}{ Moderate (+) } & \multicolumn{2}{|c|}{ Severe $(++)$} & \multirow[t]{2}{*}{$\mathbf{X}^{2}$} \\
\hline & No. & $(\%)$ & No. & $(\%)$ & No. & $(\%)$ & No. & $(\%)$ & \\
\hline Yankasa sheep & & & & & & & & & \\
\hline Overall & 149 & 34.5 & 1 & 0.2 & 249 & 57.6 & 33 & 7.6 & \\
\hline Sex & & & & & & & & & \\
\hline Male & 68 & 15.7 & 1 & 0.2 & 123 & 28.4 & 16 & 3.7 & \\
\hline Female & 81 & 18.8 & 0 & 0.0 & 126 & 29.2 & 17 & 3.9 & ns \\
\hline Age & & & & & & & & & \\
\hline$<6$ months & 4 & 0.9 & 0 & 0.0 & 9 & 2.0 & 0 & 0.0 & \\
\hline $6-12$ months & 41 & 9.5 & 1 & 0.2 & 105 & 24.3 & 18 & 4.1 & $15.709 *$ \\
\hline
\end{tabular}




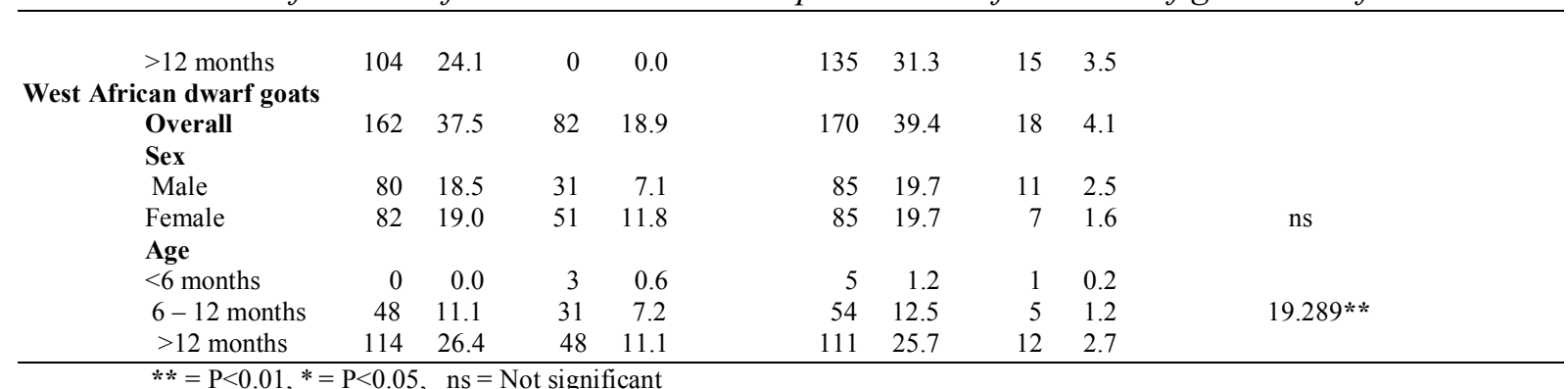

\section{Seasonal prevalence of helminthosis and eimeria in Yankasa sheep and West African dwarf goats}

The influence of season on helminthosis is shown in Table 5. Season had not significant $(\mathrm{P}<0.05)$ influence on prevalence of helminthosis and eimeria in Yankasa sheep. The highest prevalence 21.29\% was obtained in the late rainy season followed by $15.97 \%$ and $14.81 \%$ in the early rain and early dry season respectively, whereas the late dry season had the lowest prevalence of $13.43 \%$.

Season had not significant $(\mathrm{P}<0.05)$ influence on prevalence of helminthosis and eimeria in West African dwarf goats. The highest prevalence was $17.12 \%$ in late rain followed by $16.43 \%$ and $16.20 \%$ in early rain and early dry season respectively while the lowest was $12.73 \%$ in late dry season.

Table 5: Helminthosis prevalence in Yankasa sheep and West African dwarf goats by season.

\begin{tabular}{|c|c|c|c|c|c|}
\hline \multirow[b]{2}{*}{ Variables } & \multicolumn{2}{|c|}{ Not infected } & \multicolumn{2}{|c|}{ Infected } & \multirow[t]{2}{*}{$\mathbf{X}^{2}$} \\
\hline & $\mathbf{N}$ & $\%$ & $\mathbf{N}$ & $\%$ & \\
\hline \multicolumn{6}{|c|}{ Yankasa sheep } \\
\hline \multicolumn{6}{|c|}{ Seasons } \\
\hline Overall & 149 & 34.49 & 283 & 65.5 & \\
\hline Early Rain & 39 & 9.03 & 69 & 15.97 & \\
\hline Late Rain & 16 & 3.70 & 92 & 21.29 & $62.173 * *$ \\
\hline Early Dry & 44 & 10.19 & 64 & 14.81 & \\
\hline Late Dry & 50 & 11.57 & 58 & 13.43 & \\
\hline \multicolumn{6}{|c|}{ West African dwarf goats } \\
\hline \multicolumn{6}{|c|}{ Season } \\
\hline Overall & 162 & 37.5 & 270 & 62.5 & \\
\hline Early Rain & 36 & 8.33 & 70 & 16.20 & $55.532 * *$ \\
\hline Late Rain & 37 & 8.56 & 74 & 17.12 & \\
\hline Early Dry & 37 & 8.56 & 71 & 16.43 & \\
\hline Late Dry & 52 & 12.03 & 55 & 12.73 & \\
\hline
\end{tabular}

\section{Discussion:}

Helminths species of Yankasa sheep and West African dwarf goats in Lafia.

Most of the helminth species reported in this study viz; Ascaris lumbricoides, Bunostomum trigonocephalum, Chabertia, Haemonchus contortus, Oesophagostomum columbianum, Strogyloides papillosus, Trichostrongylus columbriformis, Fasciola hepatica, Paramphistomum, Moniezia expansa and Eimeria have also been reported in sheep and goats in Nigeria by Fabiyi (1970; 1973), Fakae and Chiejina (1991), Nwosu et al. (1996), Australia (Besier and Love, 2003), Bhilai (Pathak et al., 2000), France (Silvestee et al., 2000), Senegal (Ndao et al., 1991), India (Jilhendran et al., 2001). In the present study, a higher prevalence of helminthosis was observed in sheep than in the goats which is in agreement with other works in Ethiopia (Teklye, 1991) and elsewhere in the world (Waruiru et al., 2005; Asif et al., 2008) and this is assumed to be due to the grazing habit of the sheep where they graze closer to the ground fostering opportunity of exposure to parasites. In this regard, beside the grazing habit of the sheep, the communal grazing area of sheep and goats practiced in the study area could put the goats in a risk of acquiring the infection from the sheep (Dagnachew et al., 2011); furthermore, it is assumed that sheep do have a considerably higher immunological response to gastrointestinal parasites compared with that of goats (Urquhart et al., 1996). Nematodes were more prevalent in the study area than other genera which agree with Bejsovec (1991), Tembely and Hansen (1996) who reported the dominance of nematodes in their work. A significant difference in the prevalence of Haemonchus contortus has been recorded between different breeds of sheep and goats (Besier and Love, 2003; Waruiru et al., 2005; Chaudhary et al., 2007).

The main trematode species recovered from the present study were Fasciola and Paramphistomum. Durrani et al. (1981) and Malik et al. (1995), on the other hand, reported very high prevalence of fasciolosis in Jhelum valley and Punjab. Bilqees (1988) identified $F$. hepatica to be one of the most common infections in sheep but relatively less common in goats. Paramphistomum are called as rumen flukes, since a large number of 
species have been described from rumen and reticulum of domestic and wild ruminants of tropical and subtropical areas (Soulsby, 1982; Urquhart et al., 1988).

The only cestode observed in the ruminants was Monieza spp, with sheep having higher prevalence than goats, which is similar what was reported in Ethiopia (Sissay et al., 2008). The occurrence of this parasite elsewhere in the tropics has been described and is associated with ingestion of oribatid mites infected with cysts of Moniezia spp (Xiao and Herd 1992; Kumsa et al., 2011), but it was in disagreement with other reports in the country (Abebe and Esayasu, 2001; Tefera et al., 2011). The disagreement might be due to use of treatments against cestodes in the area.

The prevalence of coccidia spp reported in the current study was higher in sheep than goats. This agrees with the reports of Kanyari (1993) and Harper and Penzhorn (1999) that high prevalence of coccidiosis in Kenyan livestock sheep may possibly due to the favorable climate.

\section{Influence of helminthosis prevalence on breeds, sex and age animals}

Helminthosis may differ in importance among these animals, though no valid comparisons between the two species have been made, although the same helminths parasites have been found in both species in an area. It would seem logical that Yankasa sheep would suffer heavier infestation because they graze succulent grasses which provide a favorable environment for the development and survival of worm larvae, while West African dwarf goats prefer to browse trees and shrubs. Results obtained in this study showed, the helminthosis prevalence in West African dwarf goats was lower as compared to Yankasa sheep, although there was not significant differences among the two breeds and those that were not infected with helminthosis. This agrees with the reports of Baker et al. (2001) who reported breeds differences in small ruminants from studies involving the small east African breeds which emerged as resistant when compared with other breeds. Lah (2003) reported that there was a significant differences among Sheep and Goat breeds in helminthosis prevalence. Chiroma (1996), Hielscher et al. (2006) and have stated that susceptibility to parasites vary according to breeds. However influence of sex was not significantly different which according to Boag and Thomas (1971), sex does not really appear to have a direct influence on epidemiology of helminthosis excepts for the contribution in which the ewe in particular makes to pasture contamination and transmission of infection during pregnancy and lactation through peri-paturient rise in her faecal egg output. The study further revealed that sex of the animal did not show significant association with the prevalence of the parasites and degree of EPG. The absence of association between sexes is consistent with previous reports (Keyyu et al., 2003; Regassa et al., 2006; Ghanem et al., 2009). However, Dagnachew et al. (2011) reported a higher prevalence of helminth infection in females. In contrast, Gualy et al. (2006) and Raza et al. (2007) have documented higher prevalence of helminth infection in rams.

The observed significant effect of age Yankasa sheep and West African dwarf goats on helminths prevalence corroborates the reports of (Tesfaheywet, 2012) who stated that, there is a relationship between infection and age of animals. He further documented that, there are instances where younger animals were reported to be resistant to parasitic infection. The higher prevalence rate observed among the older than the younger animals, in this study implies that older animals are more susceptible to helminthosis. This tallies with Umoh et al. (1982) who reported that parasitism is more prevalent in animals of 24 months and above than in those of lower ages. On the contrary, Lah (2003) and Dafur (2006) reported higher prevalence in younger than adult sheep and goats respectively. Dough and Morum (1993) reported higher infection rates in lambs than in older sheep.

\section{Influence of helminthosis prevalence by count on breed, sex and age of animals}

This study has shown the presence of mixed infection characterized by the presence of single or multiple helminth genera both in Yankasa sheep and West African dwarf goats and this is in agreement with the findings of other researchers in other countries (Genene, 1994; Abebe and Esayasu, 2001; Haileleul, 2002; Regassa et al., 2006; Tefera et al., 2011; Kumsa et al., 2011) and elsewhere (Asif et al., 2008; Agyei, 2003; Githigi et al., 2005; Waruru et al., 2005). This poly-parasitism has been suggested to be an important cause of morbidity and loss of production in sheep and goats (Kumsa et al., 2010). Moreover, the presence of interaction and compromization of the immune system of the host by poly-parasitism has been described to increase their susceptibility to other diseases or parasites (Wang et al., 2006). Hence, poly-parasitism is an important problem of sheep and goats production in the current study area.

\section{Influence of type of infection on breed, sex and age of animals}

The results of this study showed a not significant difference among the sex and season of the breeds and a significant difference among the age of the animals which was similarly reported by Tefera et al. (2011). The observed threshold level of eggs numbers in this study area may be regarded as low to moderate that mainly manifested as subclinical infection or managerial ability (Waruiru et al., 2005). The effect of these infections 
can be aggravated by the frequent used of anti-helminthes and management system adopted by the livestock owner. This is described as most economically important form of infection since it occurs in most of the cases leading to unthriftness and animals are more susceptible to other infections and are continuously contaminating pastures (Ocaido et al., 1996).

\section{Influence of seasons on animals}

The study showed that 65.5 and $62.5 \%$ of Yankasa sheep and West African dwarf goats respectively are infested with one or more helminths in wet and dry season. This finding is lower than the results of other surveys in sheep and goat carried out in Eastern (Abebe and Esayasu, 2001; Sisay et al., 2007), Western (Regassa et al., 2006; Tefera et al., 2011), Central (Kumessa et al., 2011), Northern (Genene, 1994; Tesfaye, 1998) and Southern (Hailelue, 2002; Amenu, 2005) Ethiopia. The decreased in the GIT helminthiasis in the present study compared with the other studies in the country could be due to the existence of unfavorable climatic or environmental factors that could support prolonged survival and development of infective larval stage of most helminths (Rossanigo and Grunder, 1995; Andrews, 1999). Lindqvist et al. 2001 also attributed several factors i.e., warmer and wetter grazing seasons, the greater time animals spend on pasture, ineffective deworming practices or the development of antihelmintic resistance in parasites. Because most of these studies are conducted in the part of the country where there is a very favorable humidity and temperature which generally supports parasitic growth and development (Regassa et al., 2006; Dagnachew et al., 2011). There existed direct relationship between moisture and prevalence of parasitosis (Regassa et al., 2006) while desiccation suppress the development and growth of parasite (Dagnachew et al., 2011) thereby reducing the infection rate.

This study have shown that the parasitic load in the wet season is significantly higher than the dry season owing to the general understanding that moisture is one of the bionomic factor that support the development of the infective stage of most parasites (Hansen and Perry, 1994; Urquhart et al., 1996; Ejembi, 2009) which is also true phenomenon in sub-Saharan Africa (Teklay, 1991). Furthermore, management system (Regassa et al., 2006) could also contribute in the difference in the prevalence. High rain fall also helps in providing suitable molarities of salt present in soil, which is an important factor for ecdysis. Nonetheless, the present study was higher in prevalence in sheep and consistent in goats compared with the report by Dagnachew et al. (2011) from Northwest Ethiopia. This discrepancy could be attributed to difference in the management system.

\section{Conclusion}

In general, the overall prevalence of gastrointestinal helminth parasites in the study area indicates gastrointestinal helminthosis to be important heath problem due to its high prevalence and occurrence of polyparasitism. The present study showed that older sheep and goats were more susceptible to helminthosis than younger once and considerable relation between species of animals, study period (season) and age groups. In both sheep and goats, the nematode parasites were the most predominant parasites followed by trematode and the cestode. The sheep are more susceptible to helminthosis than goats. Majority of the sheep and goats were infected by two and more parasite types with some animals showing pure infection.

\section{References}

